\title{
Iron sufficiency in the population of Northern Ireland: estimates from blood measurements
}

\author{
BY J. J. STRAIN ${ }^{1}$, K. A. THOMPSON ${ }^{2}$, M. E. BARKER ${ }^{2}$, AND D. G. M. CARVILLE \\ ${ }^{1}$ Biomedical Sciences Research Centre and ${ }^{2}$ Centre for Applied Health Studies, University of Ulster \\ at Coleraine, Cromore Road, Coleraine BT52 ISA, Northern Ireland
}

(Received 24 July 1989 - Accepted 5 February 1990)

\begin{abstract}
Estimates of iron status in a random sample ( 218 men, 283 women) of the Northern Ireland population (aged 18-64 years) were obtained from blood measurements. Multiple criteria were used to determine Fe deficiency and body Fe stores were calculated as an index of Fe sufficiency. Three distinct groups with respect to Fe stores were identified on the basis of sex and menstrual status. Estimates of body Fe stores, mean (and SD), were 13.4 (SD 5.97), 5.3 (SD 6.09) and 8.5 (SD 6.72) mM for men, women aged $18-44$ years and women aged 45-64 years respectively. The prevalence of Fe-deficiency anaemia was low, ranging from $0.5 \%$ in men to $6.6 \%$ and $4.6 \%$ in the younger and older women respectively. The prevalence of Fe deficiency was low in men $(1.4 \%)$ and older women $(5.7 \%)$ rising to $11.0 \%$ in the younger group of women. The disproportionately elevated serum ferritin relative to transferrin saturation supported the suggestion that chronic inflammation might have influenced Fe status measurements in men and older women.
\end{abstract}

Iron status: Body iron stores: Inflammation

It is now recognized that the assessment of iron status in a population by using predetermined cut-off points for individual laboratory values can give misleading results. This is due to the degree of overlap in laboratory values between Fe-deficient and Fesufficient populations and the influences of inflammatory processes and dietary deficiencies of other nutrients on these values (Cook, 1986). Furthermore, the estimated prevalence of Fe deficiency can vary considerably depending on the laboratory measurement used. Cook et al. (1986) have integrated the independent measurements of Fe status to define various degrees of Fe deficiency in the US population. This use of multiple criteria was extended by these workers to include quantitative estimates of body Fe stores for each subject. Thus, information on the levels of body Fe stores of the Fe-sufficient segment of the population was also obtained.

Chronic inflammatory conditions, however, can complicate the assessment of Fe status in a population and this problem has recently been addressed by Yip \& Dallman (1988) using data from the first National Health and Nutrition Examination Survey (NHANES I) in the US. Measurement of Fe status in the latter study was based on the serum Fe: Febinding capacity ratio and erythrocyte sedimentation rate (ESR) was used as an index of inflammation.

In the present study multiple criteria and body $\mathrm{Fe}$ stores were used to estimate the $\mathrm{Fe}$ status of a random representative sample of the Northern Ireland population aged 18-64 years. These estimates were then related to indices of inflammatory conditions, i.e. elevated leucocyte count and abnormally high activity of the acute-phase reactant, caeruloplasmin (EC 1.16.3.1), in order to evaluate the influence of inflammation on Fe status measurements. 


\section{SUBJECTS AND METHODS}

Non-fasted venous blood samples (taken only in the evening) were obtained from a representative sample of the Northern Ireland population (aged 18-64 years). Day-to-day differences in measurements of Fe status in the serum of healthy subjects appear to be largely influenced by diurnal variations (Beaton et al. 1989). The sample of subjects was obtained through two stages. At the first stage, a random sample of addresses, stratified by population density of three sub-regions, was selected from the computerized sampling frame based on Household Valuation Rates obtained from the Department of Finance and Personnel, Policy Planning and Research Unit (PPRU; Stormont, Belfast). The second stage sampling involved randomly selecting an individual from each household using the Kish (1965) sampling method which is designed to produce a sample reflecting the age and sex distribution of the population from which the sample is drawn. A total of 522 subjects agreed to give blood, comprising $67 \%$ of the effective sample. The sample of respondents who gave blood was compared with those who did not give blood, and it was found that there were no significant differences in the age, sex and socioeconomic group distributions. Further details of subjects and sampling procedures are given in Barker et al. (1989).

Blood samples were processed immediately and the serum or plasma was separated. Whole blood and serum were cooled and transported for analysis at the Royal Victoria Hospital (Belfast) laboratories, which subscribe to the UK National External Quality Assessment Scheme. Only those samples analysed within $48 \mathrm{~h}$ of blood letting were included in the calculation of Fe status. A full haematological profile was obtained with an automated technique using a Coulter counter. Serum ferritin (SF) was measured by radioimmunoassay using antibodies raised to human spleen ferritin labelled with ${ }^{125} \mathrm{I}$ by Bolton \& Hunter (1973) reagent (Amersham International plc, Amersham, Bucks). Tests for serum $\mathrm{Fe}$, after reduction and formation of a blue complex with mercuric tripyridyltirazine, and total Fe-binding capacity (TIBC), by calculation from the unbound $\mathrm{Fe}$ remaining after the addition of a known amount of excess ferrous $\mathrm{Fe}$, were performed on the American Monitor 'Parallel' system. Transferrin saturation (TS) was calculated by expressing the serum $\mathrm{Fe}$ as a percentage of TIBC, and mean corpuscular haemoglobin concentration $(\mathrm{MCHC})$ was the haemoglobin:packed cell volume ratio, expressed as a percentage.

Multiple criteria were used to define Fe deficiency (subjects having abnormally low values of any two of SF, TS or MCHC) and Fe-deficiency anaemia (subjects having abnormally low values of any two of SF, TS or MCHC and an abnormally low haemoglobin). Serum Fe was used instead of TS in those subjects (twenty men, twenty-four women) for whom TIBC values were not available. Cut-off values were those used by Cook et al. (1986) and Bindra \& Gibson (1986).

Body Fe stores were calculated using the equations of Cook et al. (1986) as modified by Ballot et al. (1989). In normal subjects with haemoglobin (men $>130 \mathrm{~g} / \mathrm{l}$, women $>120 \mathrm{~g} / \mathrm{l}), \mathrm{SF}(>12 \mu \mathrm{g} / \mathrm{l})$ and $\mathrm{TS}(>16 \%)$ :

$$
\text { Fe stores }(\mathrm{mM})=7 \cdot 16 \times(\log \mathrm{SF}-\log 12) \text {. }
$$

In subjects with normal haemoglobin values but abnormally low SF:

Fe stores $(\mathrm{mM})=-1.43 \times$ index,

where the index was calculated by assigning a value of 1 to each of the following: SF $<9 \mathrm{~g} / 1$ and $<5 \mathrm{~g} / 1$; $\mathrm{TS}<12,<8$ and $<4 \%$.

In subjects with abnormally low haemoglobin, SF and TS:

Fe stores $(\mathrm{mM})=-0.27 \times($ median haemoglobin - observed haemoglobin $)$, 
where the median haemoglobin was taken as $150 \mathrm{~g} / 1$ for men and $140 \mathrm{~g} / 1$ for women.

In subjects with abnormally low haemoglobin but normal SF and TS:

Fe stores $(\mathrm{mM})=7 \cdot 16 \times(\log \mathrm{SF}-\log 12)-0 \cdot 27 \times$

(median haemoglobin-observed haemoglobin),

where the median haemoglobin was taken as $150 \mathrm{~g} / 1$ for men and $140 \mathrm{~g} / 1$ for women.

Plasma samples were stored frozen at $20^{\circ}$ until analysis at this laboratory for caeruloplasmin activity (Strain et al. 1989). The upper tenth percentile of the caeruloplasmin distributions (men $>930 \mathrm{U} / 1$, women $>1150 \mathrm{U} / 1$ ), a leucocyte count $>10 \times 10^{9} / 1$ (Hercberg et al. 1988) and SF $>50 \mu \mathrm{g} / 1$ (Cook et al. 1986) were used to assess the influence of inflammatory conditions on abnormally low TS and MCHC measurements. SF distributions were normalized by logarithmic transformation before statistical testing.

Ethical approval for the study was obtained from the Medical Ethical Committee of the Faculty of Medicine, The Queen's University, Belfast.

\section{RESULTS}

The measurements of $\mathrm{Fe}$ status in a representative sample, aged 18-64 years, of the Northern Ireland population are given in Table 1. Since SF levels were highly significantly affected by sex and menstrual status (Barker et al. 1989), the population was subdivided into three study groups, i.e. men, women aged 18-44 years, and women aged 45-64 years. Apart from $\mathrm{MCHC}$, other measurements of Fe status were much greater in men than in women, and haemoglobin levels, but not TS or serum Fe, reflected the differences in SF with respect to menstrual status.

As expected there was a marked difference in body Fe stores in the three groups with mean and (SD) values of 13.4 (SD 5.97) $\mathrm{mm}$ in men, 5.3 (SD 6.09) $\mathrm{mm}$ in younger women and 8.5 (SD 6.72) $\mathrm{mm}$ in postmenopausal women. These results were very similar to those found by Cook et al. (1986) for the US population.

In the current study caeruloplasmin activity and leucocyte counts for the three groups within the population were also measured and are given in Table 1.

When various methods for estimating the prevalence of Fe deficiency were compared (Table 2) it was apparent that the prevalence of Fe-deficiency anaemia, as defined by a single criterion (abnormally low haemoglobin), was much higher than the prevalence defined by multiple criteria or Fe stores (<-5.4 mM; Cook et al. 1986). The estimated prevalence by multiple criteria was low ranging from $0.5 \%$ in men to 6.6 and $4.6 \%$ in the younger and older women respectively, and was similar to the estimated prevalence by $\mathrm{Fe}$ stores for the three groups. The prevalence of Fe deficiency as defined by multiple criteria was also low in men $(1.4 \%)$ and older women $(5.7 \%)$, but was appreciably higher at $11.0 \%$ in the younger women. Storage estimates $(<0 \mathrm{~mm}$ or $<-1.8 \mathrm{~mm}$; Cook et al. 1986) of Fe deficiency differed slightly from the estimates by multiple criteria.

Estimates of Fe deficiency in men and postmenopausal women were much lower when determined by SF rather than with TS or with MCHC (Table 2). The suggestion that chronic inflammation might have influenced Fe status measurements in men and the older women, resulting in disproportionately elevated SF relative to TS, was supported by the observation that the abnormally low TS values were accompanied by moderately high ( $>50 \mathrm{~g} / \mathrm{l}$ ) SF in sixteen of twenty-one men and six of twenty-four older women, but in only five of forty-seven of the younger women (Table 3).

Sex differences in caeruloplasmin activity were apparent with men having lower values than women, and separate statistically derived cut-off points (indicating infiammatory disease) for men and women were taken from the 90 th percentile of each population 
Table 1. Measurements of iron status and inflammatory indices in subjects aged 18-64 years in Northern Ireland

\begin{tabular}{|c|c|c|c|c|c|}
\hline & & \multirow{2}{*}{$\begin{array}{c}\text { Men } \\
\text { (18--64 years) }\end{array}$} & \multicolumn{2}{|c|}{ Women } & \multirow{2}{*}{$\begin{array}{l}\text { SD within } \\
\text { groups }\end{array}$} \\
\hline & & & (18-44 years) & (45-64 years) & \\
\hline \multirow[t]{2}{*}{ Haemoglobin $(\mathrm{g} / \mathrm{l})$} & Mean & 149 & 131 & 134 & $11 \cdot 3$ \\
\hline & $n$ & 218 & 192 & 91 & \\
\hline \multirow[t]{3}{*}{ Serum ferritin $(\mu \mathrm{g} / \mathrm{l})$} & Geometric mean & 107 & 35 & 61 & $60 \cdot 12$ \\
\hline & Log mean & $4 \cdot 4$ & $3 \cdot 24$ & $3 \cdot 8$ & \\
\hline & $n$ & 218 & 192 & 91 & \\
\hline \multirow[t]{2}{*}{ TS $(\%)$} & Mean & $24 \cdot 7$ & $21 \cdot 4$ & $19 \cdot 5$ & $9 \cdot 18$ \\
\hline & $n$ & 198 & 176 & 83 & \\
\hline \multirow[t]{2}{*}{ Serum Fe $(\mu \mathrm{M})$} & Mean & $15 \cdot 9$ & $14 \cdot 3$ & $13 \cdot 1$ & $5 \cdot 31$ \\
\hline & $n$ & 217 & 190 & 91 & \\
\hline \multirow[t]{2}{*}{$\mathrm{MCHC}(\%)$} & Mean & $33 \cdot 8$ & $33 \cdot 5$ & $33 \cdot 1$ & 2.02 \\
\hline & $n$ & 218 & 192 & 91 & \\
\hline \multirow[t]{2}{*}{ Fe stores (mM) } & Mean & $13 \cdot 4$ & $5 \cdot 3$ & $8 \cdot 5$ & $6 \cdot 15$ \\
\hline & $n$ & 218 & 189 & 91 & \\
\hline \multirow{2}{*}{$\begin{array}{l}\text { Caeruloplasmin } \\
(E C 1.16 .3 .1) \\
\text { (Units } / \text { ) }\end{array}$} & Mean & 699 & 816 & 837 & $236 \cdot 9$ \\
\hline & $n$ & 203 & 165 & 80 & \\
\hline \multirow{2}{*}{$\begin{array}{l}\text { Leucocyte count } \\
\left(\times 10^{9} / 1\right)\end{array}$} & Mean & 8.9 & $8 \cdot 2$ & $7 \cdot 9$ & 3.88 \\
\hline & $n$ & 218 & 192 & 91 & \\
\hline
\end{tabular}

TS, transferrin saturation; MCHC, mean corpuscular haemoglobin concentration.

Table 2. Prevalence (\%) of iron deficiency in subjects aged 18-64 years in Northern Ireland

\begin{tabular}{|c|c|c|c|}
\hline & \multirow{2}{*}{$\begin{array}{c}\text { Men } \\
\text { (18-64 years) }\end{array}$} & \multicolumn{2}{|c|}{ Women } \\
\hline & & (18-44 years) & ( $45-64$ years) \\
\hline \multicolumn{4}{|l|}{ Fe-deficiency anaemia } \\
\hline Single criterion & $2 \cdot 3$ & $13 \cdot 5$ & $9 \cdot 8$ \\
\hline Multiple criteria & 0.5 & $6 \cdot 6$ & $4 \cdot 6$ \\
\hline Storage estimate $(<-5.4 \mathrm{~mm})$ & 0.5 & $5-8$ & $3 \cdot 3$ \\
\hline \multicolumn{4}{|l|}{ Fe deficiency } \\
\hline \multicolumn{4}{|l|}{ Single criterion } \\
\hline Serum ferritin & 1.8 & $18 \cdot 2$ & $4 \cdot 3$ \\
\hline Transferrin saturation & $10 \cdot 6$ & $26-7$ & $31 \cdot 0$ \\
\hline $\begin{array}{l}\text { Mean corpuscular haemoglobin } \\
\text { concentration }\end{array}$ & 6.9 & $14 \cdot 1$ & $8 \cdot 7$ \\
\hline Multiple criteria & $1 \cdot 4$ & $11 \cdot 0$ & $5 \cdot 7$ \\
\hline Storage estimate $(<0 \mathrm{~mm})$ & 0.9 & $18 \cdot 0$ & $6 \cdot 6$ \\
\hline$(<-1.8 \mathrm{~mm})$ & 0.5 & $13 \cdot 8$ & 6.6 \\
\hline
\end{tabular}

distribution. An epidemiologically derived cut-off point for leucocyte count (Hercberg et al. 1988) was used as an additional indicator of inflammatory processes. However, when the latter inflammatory indices were investigated in individuals with abnormally low TS values, only three of twenty-one men and one of twenty-two older women had abnormal caeruloplasmin activities while three of twenty-one men and four of twenty-four older women had abnormal leucocyte counts (Table 3). Similarly, abnormal MCHC was accompanied by abnormal caeruloplasmin activities or leucocyte counts in relatively few individuals compared with the number of individuals who had an accompanying moderately high SF. 
Table 3. The relationship between low iron indices and elevated inflammatory indices

(Ratios with percentages in parentheses)

\begin{tabular}{cccc}
\hline & & \multicolumn{2}{c}{ Iron index } \\
\cline { 3 - 4 } Subjects & Inflammatory index & TS $(<16 \%)$ & MCHC $(<32 \%)$ \\
\hline Men (18-64 years) & $\mathrm{SF}(>50 \mathrm{~g} / \mathrm{l})$ & $16 / 21(76 \cdot 2)$ & $12 / 15(80 \cdot 0)$ \\
& $\mathrm{Cp}(>930 \mathrm{U} / 1)$ & $3 / 21(14 \cdot 3)$ & $3 / 21(14 \cdot 3)$ \\
& $\mathrm{WCC}\left(>10 \times 10^{9} / 1\right)$ & $3 / 21(14 \cdot 3)$ & $2 / 15(13 \cdot 3)$ \\
Women (18-44 years) & $\mathrm{SF}(>50 \mathrm{~g} / 1)$ & $5 / 47(10 \cdot 6)$ & $3 / 27(11 \cdot 1)$ \\
& $\mathrm{Cp}(>1150 \mathrm{U} / 1)$ & $3 / 40(7 \cdot 5)$ & $2 / 26(7 \cdot 7)$ \\
& $\mathrm{WCC}\left(>10 \times 10^{9} / 1\right)$ & $7 / 47(14 \cdot 9)$ & $1 / 27(3 \cdot 7)$ \\
Women (45-64 years) & $\mathrm{SF}(>50 \mathrm{~g} / 1)$ & $6 / 24(25 \cdot 0)$ & $3 / 7(42 \cdot 9)$ \\
& $\mathrm{Cp}(>1150 \mathrm{U} / 1)$ & $1 / 22(4 \cdot 5)$ & $0 / 7(0)$ \\
& $\mathrm{WCC}\left(>10 \times 10^{9} / 1\right)$ & $4 / 24(16 \cdot 7)$ & $1 / 7(14 \cdot 3)$ \\
\hline
\end{tabular}

SF, serum ferritin; TS, transferrin saturation; Cp, caeruloplasmin (EC 1 16.3.1); MCHC, mean corpuscular haemoglobin concentration; WCC, leucocyte count.

\section{DISCUSSION}

The prevalence of Fe deficiency, as defined by multiple criteria, was only slightly higher in the Northern Ireland population at $1 \cdot 4,11.0$ and $5 \cdot 7 \%$ compared with $0 \cdot 7,10 \cdot 0$ and $4 \cdot 1 \%$ for men, premenopausal women and postmenopausal women respectively in the US population (Cook et al. 1986).

The prevalence of Fe-deficiency anaemia in the Northern Ireland population using the Fe storage estimate of Cook et al. (1986) was low at $0.5,6.6$ and $4.6 \%$ in men, premenopausal women and postmenopausal women respectively, yet higher than the respective values for the adult population in the US of $0 \cdot 2,2 \cdot 6$ and $1.9 \%$ (Cook et al. 1986). The prevalence of Fe-deficiency anaemia in Northern Ireland, however, was much lower than in Fe-deficient population subsets described within South Africa (Ballot et al. 1989), Algeria (Hercberg et al. 1988) or lacto-ovo-vegetarian East-Indian immigrants to Canada (Bindra \& Gibson, 1986).

The prevalence of Fe-deficiency anaemia observed in adult males in NHANES II was appreciably lower than the frequency of the Fe-loading gene in the US population (Kushner et al. 1984). Cook et al. (1986) have argued, therefore, that information should be collected on the Fe-sufficient as well as the Fe-deficient segments in such populations. An important advantage in calculating body $\mathrm{Fe}$ stores is that it defines the level of $\mathrm{Fe}$ sufficiency in the entire population. The level and distribution of body Fe stores in men, premenopausal women and postmenopausal women are very similar for the Northern Ireland $(13.4,5.3$ and $8.5 \mathrm{~mm}$ respectively) and US populations $(13.9,5.5$ and $10.9 \mathrm{~mm}$ respectively). Although information on the frequency of the Fe-loading gene is not available for the Northern Ireland population, it is reasonable to assume that careful monitoring of $\mathrm{Fe}$ status is warranted in this population where the high bioavailability of dietary $\mathrm{Fe}$ sources and the consumption of Fe-fortified foods, and $\mathrm{Fe}$ and ascorbate supplements (Barker et al. 1989) could lead to Fe overload, with associated problems (Gordeuk et al. 1987), in an appreciable segment of the population.

Measurements of $\mathrm{Fe}$ status in a population can be confounded by chronic inflammation which results in low TS values in combination with elevated SF levels. Indeed, up to 80 and $40 \%$ of postmenopausal women who had abnormally low TS or MCHC values respectively also had moderately elevated (> $50 \mathrm{~g} / \mathrm{l}$ ) SF levels (Table 3). Although other inflammatory indices, i.e. caeruloplasmin activity and leucocyte count, were less supportive, this suggested that chronic inflammation was an important factor in the relatively high 
prevalence of abnormally low TS or MCHC values in men and older women. Inflammation is more common among elderly individuals and in the lower socioeconomic groups. Yip \& Dallman (1988) found that in the US both Fe deficiency and inflammatory disease played a major role in the increased prevalence of anaemia among the poor, and that inflammation rather than $\mathrm{Fe}$ deficiency was the most common underlying reason for anaemia among elderly individuals. Only serum Fe of the Fe status measurements in the Northern Ireland population was significantly affected by socioeconomic status, being increased in the unemployed (Barker et al. 1989). However, $10.9 \%$ of men and $17 \cdot 1 \%$ of women had reported taking anti-inflammatory drugs (Barker et al. 1989) within 1 week of being surveyed. It is, therefore, probable that mild medical conditions in the general population were responsible for the confounding effects on individual laboratory measures of Fe status observed in the present study. The increase in SF levels with inflammatory conditions could lead to overestimation of calculated body Fe stores. Indeed, in postmenopausal women there was a highly significant $(P<0.001)$ positive correlation $(r 0.37$, Pearson) between activity of the acute-phase reactant, caeruloplasmin, and SF levels. This observation adds weight to the argument that inflammatory conditions are interacting with indices of $\mathrm{Fe}$ status, hence confounding the assessment of Fe deficiency and anaemia in the population.

The authors wish to thank Mr S. Nesbitt and Mr D.W. Neill, Department of Clinical Biochemistry, and Dr T. Lappin, Department of Haematology, The Royal Victoria Hospital, Belfast for advice and help with blood analyses and the fieldwork assistants for data collection. This work was funded by the Health Promotion Research Trust and the British Heart Foundation.

\section{REFERENCES}

Ballot, D. E., MacPhail, A. P., Bothwell, T. H., Gillooly, M. \& Mayet, F. G. (1989). Fortification of curry powder with $\mathrm{Na} \mathrm{Fe(III)} \mathrm{EDTA} \mathrm{in} \mathrm{an} \mathrm{iron-deficient} \mathrm{population} \mathrm{:} \mathrm{initial} \mathrm{survey} \mathrm{of} \mathrm{iron} \mathrm{status.} \mathrm{American} \mathrm{Journal} \mathrm{of} \mathrm{Clinical}$ Nutrition 49, 156-161.

Barker, M. E., McClean, S. I., McKenna, P. G., Reid, N. G., Strain, J. J., Thompson, K. A., Williamson, A. P. \& Wright, M. E. (1989). Diet, Lifestyle and Health in Northern Ireland, pp. 15 212. Coleraine: University of Ulster.

Beaton, G. H., Corey, P. N. \& Steele, C. (1989). Conceptual and methodological issues regarding the epidemiology of iron deficiency and their implications for studies of the functional consequences of iron deficiency. American Journal of Clinical Nutrition 50, 575-588.

Bindra, G. S. \& Gibson, R. S. (1986). Iron status of predominantly lacto-ovo vegetarian East Indian immigrants to Canada: a model approach. American Journal of Clinical Nutrition 44, 643-652.

Bolton, A. E. \& Hunter, W. M. (1973). The labelling of proteins to high specific radioactivities by conjugation to a ${ }^{125}$ I-containing acylating agent: application to the radioimmunoassay. Biochemical Journal 133, $529-539$.

Cook, J. D. (1986). Assessment of iron status. In Proceedings of the XIII International Congress of Nutrition, pp. 526-529 [T. G. Taylor and N. K. Jenkins, editors]. London: John Libbey.

Cook, J. D., Skikne, B. S., Lynch, S. R. \& Reusser, M. E. (1986). Estimates of iron sufficiency in the US population. Blood 68, 726-731.

Gordeuk, V. R., Bacon, B. R. \& Brittenham, G. M. (1987). Iron overload: causes and consequences. Annual Review of Nutrition 7, 485-508.

Hercberg, S., Galan, P., Assami, M. \& Assami, S. (1988). Evaluation of the frequency of anaemia and irondeficiency anaemia in a group of Algerian menstruating women by a mixed distribution analysis : contribution of folate deficiency and inflammatory processes in the determination of anaemia. International Journal of Epidemiology 17, 136-141.

Kish, L. (1965). Survey Sampling, pp. 398-401. New York: Wiley.

Kushner, J., Edwards, C., Griffen, L., Dadone, M. \& Skolnick, M. (1984). Incidence of homozygosity for HLAlinked hemochromatosis in healthy young blood donors. Blood 64, 40a.

Strain, J. J., Carville, D. G. M., Barker, M. E., Thompson, K. A., Welch, R. W., Young, P. \& Rice, D. A. (1989). Smoking and blood antioxidant enzyme activities. Biochemical Society Transactions 17, 497-498.

Yip, R. \& Dallman, P. R. (1988). The roles of inflammation and iron deficiency as causes of anaemia. American Journal of Clinical Nutrition 48, 1295-1300. 